\title{
Does occupational status matter? Examining immigrants' employment in their intended occupations
}

\author{
Kristyn Frank \\ Department of Sociology and Anthropology \\ University of Guelph \\ kfrank78@hotmail.com
}

\begin{abstract}
Research examining the economic integration of immigrants to Canada primarily focuses on earnings differentials between the native-born and foreign-born populations. Although some studies examine occupational matching among immigrants, broad levels of occupational classification are employed. This paper has two objectives: (1) to examine occupational matching for the immigrant population at a precise level of classification and (2) to broaden the focus of immigrant employment research by considering whether characteristics of their intended occupations influence the likelihood of an occupational match. Results indicate that immigrants seeking high-status occupations are significantly less likely to obtain a match than those seeking low-status occupations.
\end{abstract}

Keywords: immigrant integration, immigrant employment, occupation, Longitudinal Survey of Immigrants to Canada.

\section{Résumé}

La recherche qui étudie l'intégration économique des immigrants au Canada se concentre principalement sur les différences dans les gains entre les personnes nées au pays et celles nées à l'étranger. Bien que quelques études examinent le jumelage professionnel parmi la population immigrante, elles se servent d'une grande fourchette de classifications des professions. Cet article a deux objectifs : (1) étudier le jumelage professionnel de la population d'immigrants à un niveau précis de classification et (2) agrandir la portée de la recherche sur l'emploi de la population d'immigrants en considérant si les caractéristiques de leurs domaine professionnels choisis influencent les chances d'un jumelage professionnel. Les résultats indiquent que les immigrants à la recherche de profession de haut statut ont considérablement moins de chance d'obtenir un jumelage professionnel que ceux qui recherchent des emplois de bas statut.

Mots-clés: intégration immigrante, emploi de la population d'immigrants, profession, Enquête longitudinale auprès des immigrants du Canada.

\section{Introduction}

The successful economic integration of immigrants has become an increasing concern within Canadian society. Immigrants often arrive with professional credentials, train- 
ing, and skill sets relevant to Canada's labour market and a willingness to work in occupational sectors in need of workers (Basran and Zong 1998; Man 2004). Despite these qualifications, many immigrant professionals continue to report difficulties in obtaining employment in occupations for which they are trained (Basran and Zong 1998; Boyd and Thomas 2001; Man 2004). The study of immigrants' economic integration largely focuses on earnings differentials between the immigrant and native-born populations. Despite concern about immigrants' underemployment, there has been little examination of occupational matching, particularly at precise levels of occupational classification.

Previous research has addressed the difficulties immigrants experience in obtaining employment in occupations for which they are already trained (McDade 1988; Basran and Zong 1998; Li 2001; Bauder 2003; Alboim et al. 2005). However, those that examine occupational match within the immigrant population either use occupational match as a predictor of earnings (e.g., Goldmann et al. 2009) or employ broad occupational classifications such as skill type or skill level (Thompson 2000; Grondin 2007). These levels of classification are typically "broad and may hide some skill variations" (Reitz 2001a: 17). Studies that focus on occupational matching typically examine whether a match occurs between immigrants' pre-migration and post-migration employment. This paper will instead assess whether immigrants obtain employment that matches their intended occupations $^{1}$ upon arrival, examining this type of match at the fairly specific (four-digit) unit group level of the 2001 National Occupational Classification (NOC; HRSDC 2001). There is a need for more refinement in the measurement of immigrants' employment outcomes, as knowledge of employment rates and earnings differentials do not necessarily indicate immigrants' success in obtaining their desired employment. Through the examination of occupational matching, this study provides a meaningful measurement of recent immigrants' occupational attainment in Canada.

Previous studies examining immigrants' economic integration in Canada are largely focused on the relationships between various human capital characteristics and employment success (e.g., Thompson 2000; Reitz 2001a, 2001b). The influence of immigrants' ascribed characteristics on their earnings or other occupational outcomes has also been studied, usually examining discrimination based on sex or race ( $\mathrm{Li} 2000$; Frenette and Morissette 2003). While this paper does include these factors as potential predictors of the likelihood of an occupational match, characteristics of immigrants' intended occupations are also considered as potential predictors of a match. Although the type of employment highly skilled immigrants seek is frequently discussed as a factor in their employment success, researchers often focus on only those individuals who seek a specific occupation, typically concentrating on those who intend to work as physicians or engineers (Boyd and Thomas 2001; Boyd and Thomas 2002; Boyd and Schellenberg 2007). This paper examines occupational match across all occupational groups. The most frequently stated intended occupations of recent immigrants and the most frequently held occupations of those who do not obtain an occupational match during the observed period are also presented.

1. Intended occupation is stated on an individual's application for immigration. These data were merged into the LSIC data set from Citizenship and Immigration Canada's Field Operation Support System. 


\section{Previous literature and theoretical perspective}

Literature examining the occupational attainment of immigrants to Canada primarily focuses on the issue of foreign credential recognition (McDade 1988; Basran and Zong 1998; Li 2001; Reitz 2001a; Fong and Cao 2009). Within the literature that examines this issue there has been increasing attention given to immigrant professionals and occupation-specific issues (Basran and Zong 1998; Boyd and Thomas 2001, 2002). Some key variables emerge in the literature as fundamental to the study of immigrants' success in the Canadian labour market.

Many studies identify deficiencies in human capital such as proficiency in an official language or lack of Canadian work experience as at least partly responsible for the employment difficulties faced by immigrants (Thompson 2000; Reitz 2001a, 2001b). Others assert that obstacles to immigrants' employment are due to structural barriers which systematically exclude some immigrants from entry into a profession by devaluing their foreign credentials (McDade 1988; Basran and Zong 1998; Pendakur and Pendakur 2000; Kazemipur and Halli 2001; Reitz 2001a; Bauder 2003; Li 2003; Aydemir and Skuterud 2005). Immigrants' educational credentials are a major focus of the literature examining the issue from a human capital perspective, with particular attention given to those with a university education. Despite the relatively high levels of education recent cohorts of immigrant professionals possess, they generally are not found to gain access to high-paying jobs in Canada (Frenette and Morissette 2003). However, Fong and Cao (2009) assert that differences in earnings returns to foreign credentials are partly dependent on whether an immigrant works in a professional or non-professional occupation. Thus, the alignment between intended occupation and the occupation acquired in Canada appears to be affected by the type of occupation sought. In this respect, whether or not an immigrants' credentials are acknowledged within the Canadian labour market may depend on employers' assessments of the relevancy and appropriateness of foreign training and education. Therefore, immigrants who intend to work in high status, professional occupations in Canada may not anticipate the devaluation of their credentials.

Similar to the findings on returns to foreign education, some studies have determined that foreign work experience also receives lower financial returns than Canadian work experience (Reitz 2001a; Aydemir and Skuterud 2005). This finding is consistent across studies of earnings and occupational attainment, indicating that immigrants' work experience is largely unrecognized by Canadian employers. Proficiency in an official language is also a common focus of human capital literature. Strong proficiency in English or French is consistently found to be beneficial to immigrants' employment success in Canada (Abu-Laban 1992; Thompson 2000; Kazemipur and Halli 2001; Grondin 2007; Boyd and Cao 2009).

Discrimination has also been examined as a potential obstacle to immigrants' employment success in Canada, with particular attention paid to the effects of race and sex (Reitz 2003b; Hou and Balakrishnan 2004; Galabuzi 2006; Pendakur and Pendakur 2007; Fuller and Vosko 2008; Li 2008). Research from the United States has pointed to the theory of discrimination as a "mediating process between structural attributes of labor markets" and the inequality experienced by subordinate groups (Tomaskovic-Devey et al. 2005; Roscigno et al. 2007: 19). The discrimination perspective, then, "attributes the inferior position of some ... minority groups to the socio-economic structure of society," which not only excludes but also deters minority groups from actively participating in 
"mainstream" society (Hou and Balakrishnan 2004: 274). Visible minority immigrants are found to fare worse than non-visible minority immigrants and Canadian-born whites in terms of earnings (Pendakur and Pendakur 2000; Anisef et al. 2003; Hou and Balakrishnan 2004). Sex discrimination is also apparent as immigrant women generally obtain lower paying and less stable employment than immigrant men in the Canadian labour market (Man 2004; Fuller and Vosko 2008). These findings are similar to research examining race and sex discrimination in the United States. Kaufman (2002), for example, finds that African-American men obtain "race-typed” employment in low-skill jobs.

Although not discussed extensively in the Canadian literature on the economic integration of immigrants, the process of social closure may also be a contributing factor to immigrants' difficulties in the Canadian labour market. Weber's (1968) concept of social closure provides a theoretical framework that can aid in understanding why dominant groups may prevent the entrance of others into certain spheres of society. Weber (1968: 139) describes his theory of social closure as a process in which access to certain positions in society is "closed against outsiders so far as ... participation of certain persons is excluded, limited, or subjected to conditions." Social closure is identified as a "two-sided process," where one social group excludes other from "legal access to scarce and valued resources," or where a group attempts to take such resources from other groups (also referred to as usurpationary social closure; Hunter 1986: 45).

Parkin (1979) elaborates on Weber's exposition of this concept, paying particular attention to the power exercised by occupational groups. He explains that an occupational group's exclusion of others is practiced in an effort to maintain the group's privilege and social position. Some research from the United States employs this perspective, largely focusing on the process of social closure in the examination of gender and race discrimination (e.g. Roscigno et al. 2007) as well as age (Roscigno et al. 2007). Weeden (2002) also examines the effects of social closure on earnings inequality and finds that, while earnings are influenced by social closure, in part through limiting the number of individuals qualified for certain occupations, this is not the case for all occupations. Weeden (2002: 92) states that "[the] professions, in particular, benefit more than other occupations" from the process of social closure. Thus, higher status occupations are likely to have more entrenched and effective processes of social closure than other occupations. With respect to the immigrant population in particular, research appears to have shifted to an examination of the effects of ethnic ties (Elliott and Smith 2001; Sanders et al. 2002). This research primarily examines usurpationary closure (a "bottom-up" perspective) in which immigrants' social networks are found to provide a system of employment that provides immigrant workers with work experience within the "ethnic economy" (Sanders et al. 2002: 283).

The theory of social closure proposed by Weber (1968) is largely based upon the notion that the dominant group (or groups) in society act to maintain power and status through limiting the opportunities available to others. This perspective may provide an explanation of the difficulties experienced by immigrants in the Canadian labour market, particularly if they seek high-status occupations. Because the labour market itself has a number of different status groups (i.e. different occupations), organizations that regulate occupations act to create barriers to non-members. Thus, immigrants may be excluded from highly valued, high-status occupations due to the process of social closure. This is evidenced by Weeden's (2002) finding indicating that the professions obtain greater benefits from social closure than other occupations. Thus, the examination of this theory will be focused on the occupational characteristics of immigrants' intended occupations. The 
expected outcome, based on the assumption that higher status occupations have more effective and active processes of social closure to maintain their status, is that the higher the status or complexity of an immigrant's intended occupation, the less likely it is that he or she will obtain a job match. Thus, this paper will test the theory of social closure in conjunction with the discrimination perspective and human capital theory to examine a variety of potential predictors of occupational match among recent immigrants to Canada.

\section{Data and methods}

Three waves of data from the Longitudinal Survey of Immigrants to Canada (LSIC) are utilized for the data analyses. The LSIC is a project designed jointly between Citizenship and Immigration Canada and Statistics Canada under the Policy Research Initiative (Statistics Canada 2006). The main objective of the LSIC is to study recent immigrants' experiences when adapting to Canadian society during their first four years after arrival. This survey provides data regarding immigrants' social and economic characteristics which are relevant to understanding their integration. Questions asked of LSIC respondents address their situations both prior to arrival in Canada and at the time of each interview. In addition, the LSIC reports information regarding immigrants' employment between interviews.

The three waves of the LSIC account for a recent cohort's first four years in Canada. The target population for the LSIC represents immigrants who arrived between October 1, 2000 and September 30, 2001, who were 15 years of age or older at the time of arrival, and who landed from abroad after applying through a Canadian mission abroad. These criteria account for approximately 164,200 of the 250,000 immigrants to Canada during this time period (Statistics Canada 2006). A representative sample of 20,300 immigrants was selected in order to produce reliable estimates. The Field Operation Support System (FOSS) administrative database from Citizenship and Immigration Canada was the sampling frame for the LSIC. Some of the data in the LSIC are also obtained from the FOSS database (e.g., intended occupation).

The LSIC interviewed immigrants at three separate times: six months, two years, and four years after landing in Canada. Only those who responded to the wave one interview were traced for the second wave of interviews. The first wave of the LSIC was conducted between April 2001 and May 2002. The majority of interviews (68 per cent) were conducted face-to-face while the remaining interviews were conducted over the phone for various reasons (e.g., location of respondent, language requirements). Interviews were conducted in one of the fifteen languages most frequently spoken by the target population. ${ }^{2}$

Following the wave one interviews, 12,040 respondent records were determined to be complete enough to be kept in the final data file. Non-respondents included those who were located but refused to participate $(2,120)$, "unresolved" cases in which the respondent could not be located (5,751), and "out of scope" individuals who were deceased, institutionalized, or no longer resided in Canada (389; Statistics Canada 2006). The sample size decreased from 12,040 respondents in wave one to 7,716 by wave three.

2. Languages used in interviews include English, French, Chinese (Mandarin and Cantonese), Punjabi, Farsi/Dari, Arabic, Spanish, Russian, Serbo-Croatian, Urdu, Korean, Tamil, Tagalog and Gujarati. These languages cover approximately ninety-three per cent of the immigrant population in Canada (Statistics Canada 2006). 
The LSIC is a confidential data file and is accessible to researchers only through a Statistics Canada research data centre. ${ }^{3}$ The sample weights and bootstrap weights provided by Statistics Canada are both employed in this research. The sample weights are applied to the descriptive data and have been standardized to correspond with the actual sample size. Bootstrap weights are used for the tests of significance in the logistic regression analysis, providing an estimation of variance in the significance tests.

Three limitations which are relevant to the scope of this study have been applied to the LSIC sample. First, because immigrants seeking employment are the population of interest, the sample includes only those immigrants between the ages of 25 and 64 at the time of first interview. This limitation has been applied by others (e.g., Li 2008) as it is typically identified as the "prime" working age group in which most individuals have completed their education and are not yet retired. Secondly, only those respondents who have stated an intended occupation are included in the study. This restriction is applied in accordance with the dependent variable which indicates whether or not an immigrant has obtained employment in his or her intended occupation. The sample also includes only those respondents who have held at least one job since arriving in Canada. This limitation is applied to the sample in an attempt to examine only those immigrants who have participated in the Canadian labour force in some capacity. Combined, these limitations result in a final sample size of 2,684 .

Due to the limitations applied to the sample, the results of these analyses are representative of a somewhat unique group of recent immigrants. Not only is the sample used representative of a specific cohort of immigrants, it is also limited to individuals who states an intended occupation when applying for entry into Canada. Principal applicants in the skilled worker category largely represent those who state an intended occupation. Thus, these issues should be kept in mind when making inferences from these results.

The independent and intervening variables utilized in the logistic regression analysis represent three different sets of variables. The first set of variables represents ascribed and demographic characteristics including sex, age, visible minority status, immigrant admission class, and whether or not the respondent immigrated to a major Census Metropolitan Area (CMA). These variables are first entered in Model 1 to ascertain the effects of ascribed and demographic characteristics without controlling for other characteristics. Model 2 then adds a second set of variables representing human capital, allowing for an examination of the relationships between these variables and the dependent variable as well as an indication of whether controlling for human capital variables affects relationships between the variables entered in Model 1 and the likelihood of a job match. The human capital variables include the highest level of education obtained outside of Canada, English and French language proficiency, and previous experience in one's intended occupation prior to immigration. The third set of variables, entered in Model 3, represents occupational characteristics associated with immigrants' intended occupations. The occupational characteristics examined are socio-economic status (SES) scores, calculated in a similar manner as Blishen (1967) scores, and occupational aptitudes scores identified in the Career Handbook of the 2001 NOC. Again, the addition of these variables in Model 3 allows for an examination of whether controlling for occupational characteristics changes the relationships between previously entered variables and the dependent variable. Refer to Appendix A for variable definitions and coding.

3. The LSIC data were analyzed at the South Western Ontario Research Data Centre. The results and views expressed here do not represent the views of Statistics Canada. 
Table 1. Selected characteristics of the sample.

\begin{tabular}{|c|c|c|c|c|c|}
\hline Variable & Frequency & Per centage & Mean & SD & Median \\
\hline \multicolumn{6}{|l|}{ Sex } \\
\hline Male & 1,972 & 73.5 & & & \\
\hline Female & 712 & 26.5 & & & \\
\hline Age at Immigration & 2,684 & 100.0 & 35.3 & 6.7 & 34 \\
\hline \multicolumn{6}{|l|}{ Visible Minority Status } \\
\hline Yes, visible minority & 1,982 & 73.8 & & & \\
\hline No, not visible minority & 699 & 26.2 & & & \\
\hline \multicolumn{6}{|l|}{ Region of Origin } \\
\hline Africa & 291 & 10.8 & & & \\
\hline Asia & 1,576 & 58.7 & & & \\
\hline Caribbean, Central \&South America & 171 & 6.4 & & & \\
\hline Europe & 526 & 19.6 & & & \\
\hline North America & 37 & 1.4 & & & \\
\hline Middle East & 69 & 2.6 & & & \\
\hline Oceania & 14 & 0.5 & & & \\
\hline \multicolumn{6}{|l|}{ Immigrant Class } \\
\hline Business Class & 42 & 1.6 & & & \\
\hline Family Class & 130 & 4.8 & & & \\
\hline Provincial Nominee & 27 & 1.0 & & & \\
\hline Refugee/Other Class & 31 & 1.1 & & & \\
\hline Skilled Worker & 2,454 & 91.4 & & & \\
\hline \multicolumn{6}{|l|}{ Lives in Major CMA } \\
\hline - & 2,016 & 75.1 & & & \\
\hline No & 666 & 24.8 & & & \\
\hline \multicolumn{6}{|l|}{ Highest Level of Education } \\
\hline High School or Lower & 128 & 4.8 & & & \\
\hline Some Trade School, College or Univ. & 124 & 4.6 & & & \\
\hline Trade School, College, or Apprenticeship & 260 & 9.7 & & & \\
\hline Bachelor's Degree & 1,352 & 50.4 & & & \\
\hline Master's, Professional, or Doctoral Deg. & 817 & 30.4 & & & \\
\hline 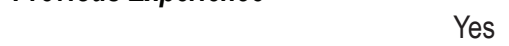 & 903 & 33.6 & & & \\
\hline No & 1,781 & 66.4 & & & \\
\hline
\end{tabular}

Note: Sample size $=2,684$.

Table 2. Five most commonly stated intended occupations: NOC Unit Group Level.

\begin{tabular}{lccr}
\hline \multicolumn{1}{c}{ Occupational Title } & NOC Code & Frequency & $\begin{array}{c}\text { Percentage of } \\
\text { Sample }\end{array}$ \\
\hline Computer Programmers and Interactive Media Developers & 2174 & 277 & 10.3 \\
Electrical and Electronics Engineers & 2133 & 179 & 6.7 \\
Mechanical Engineers & 2132 & 171 & 6.4 \\
Information Systems Analysts and Consultants & 2171 & 164 & 6.1 \\
Civil Engineers & 2131 & 103 & 3.8 \\
\hline Total & & 894 & 33.3 \\
\hline
\end{tabular}

Note: Total sample size $=2,684$. 


\section{Figure 1. Percentage of occupational matches by NOC Levels of Occupational Classification.}

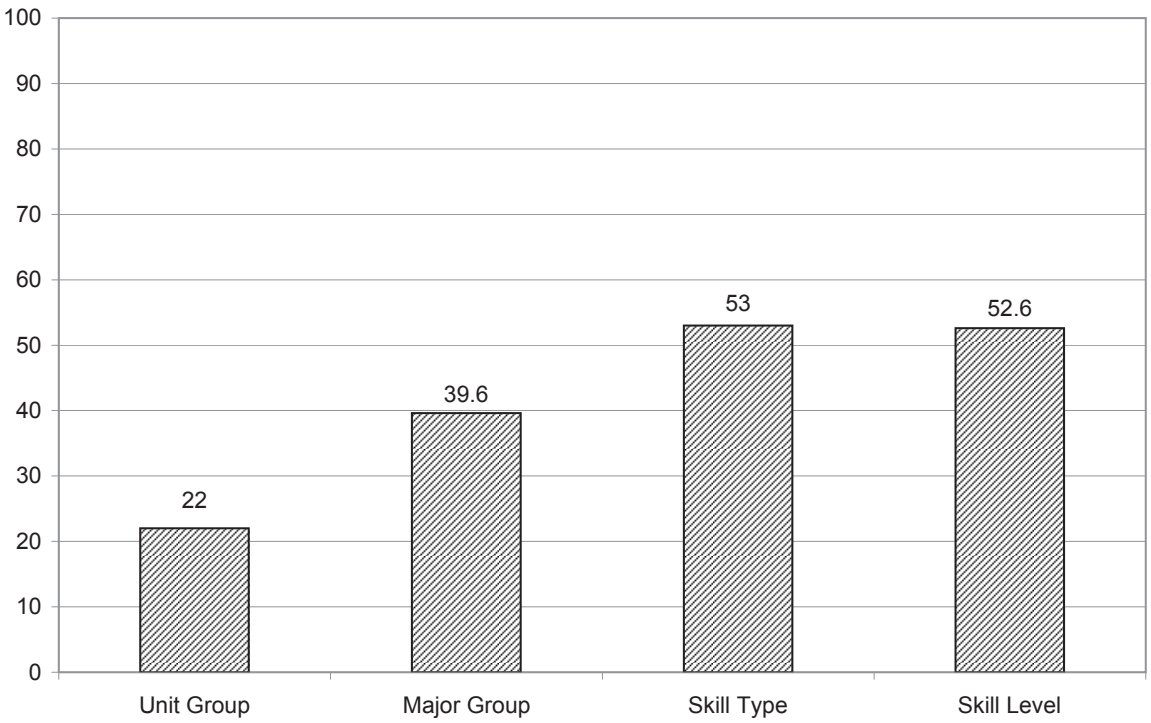

Levels of Classification: Unit Group: Four-digit level of NOC; Major Group: Two-digit level of NOC (26 groups); Skill Type: One-digit level of NOC (10 groups); Skill Level: Four skill levels:

(a) University degree, (b) college/CEGEP/ Apprenticeship (2-5 years), (c) 1-4 years secondary school education/ up to 2 years on-the-job training, (d) No educational pre-requisites/short onthe-job training. Management occupations are not associated with a specific education/training requirement in NOC's skill level classification.

Logistic regression analysis is employed in this study, as the dependent variable is binary. This variable indicates whether or not an immigrant has obtained employment in his or her intended occupation at any point since arriving in Canada (occupational match coded 1, otherwise coded 0 ) and is derived by determining if any job held since an immigrant's arrival in Canada matches his or her intended occupation. The unit group level of occupations in the 2001 NOC is used to classify the occupations. Due to the fact that the LSIC reports 1991 Standard Occupational Classification (SOC) codes for jobs held since immigration and 2001 NOC codes for immigrants' intended occupations, all jobs held since immigration were coded into NOC codes with the use of a concordance table. In addition, the vast majority of respondents examined in this analysis arrived in

\section{Table 3. Most recently held occupations among immigrants without an} occupational match.

\begin{tabular}{lccc}
\hline \multicolumn{1}{c}{ Occupational Title } & NOC Code & Frequency & $\begin{array}{c}\text { Percentage } \\
\text { of Sample }\end{array}$ \\
\hline Information Systems Analysts and Consultants & 2171 & 95 & 4.6 \\
Retail Salespersons and Sales Clerks & 6421 & 64 & 3.1 \\
Post-Secondary Teaching and Research Assistants & 4122 & 53 & 2.6 \\
Electronic Service Technicians & 2242 & 51 & 2.4 \\
Retail Trade Managers & 0621 & 44 & 2.1 \\
\hline Total & & 307 & 14.8 \\
\hline
\end{tabular}

Note: Sample size of immigrants without a job match within first four years in Canada $=2,084$. 
Canada with the appropriate level of education or training required for their intended occupations. $^{4}$

\section{Findings}

Due to the sample limitations outlined above, some characteristics of the group studied are skewed. As presented in Table 1, there is an over-representation of males, visible minorities, and skilled worker immigrants in this sample. Immigrants in the sample are also highly educated with about 80 per cent holding a Bachelor's degree or higher-level degrees. This is indicative of the sample represented here; that is, a large proportion of respondents included in the survey are individuals who immigrated to Canada under the "Skilled Worker" class. In addition, the previous work experience variable indicates that only about one third worked in their intended occupations prior to arriving in Canada. In addition, three quarters of individuals studied immigrated to a major CMA (i.e., Montreal, Toronto, or Vancouver).

The descriptive analysis of intended occupations reveals that the most common intended occupations for this cohort are computer programmers and interactive media developers. The data in Table 2 also indicate that one third of respondents intend to obtain employment in professional occupations in the natural and applied sciences (NOC major group 21). Thus, a large portion of this cohort of immigrants arrived in Canada seeking employment in occupations that require a university degree. ${ }^{5}$ Figure 1 also illustrates that less than one quarter (22 per cent) of immigrants who arrived between 2000 and 2001 obtained employment in their specific intended occupations (unit group level) within their first four years in Canada. However, when occupational match is examined at broader levels of classification the percentage of immigrants with a match increases. Thus, conclusions regarding immigrants' success in obtaining occupational matches based on broad levels of occupational classification can be misleading.

In an effort to gain a greater understanding of the employment of immigrants without an occupational match, Table 3 presents the five most frequently held occupations for this sub-sample. While the distribution of occupations is fairly wide, the most common employment among immigrants without an occupational match is as information systems analysts and consultants (4.6 per cent of the non-match sub-sample), followed by retail salespersons and sales clerks (3.1 per cent of the sub-sample). Interestingly, the occupational classification of "information systems analysts and consultants" is also one of the most frequently stated intended occupations, indicating that many immigrants who intend to work in another field of employment are often able to find employment in this occupation. This may be the result of issues relating to the recognition of foreign credentials, indicating that those who intended to work in other occupations underestimated how readily their credentials would have been accepted in the Canadian labour market. It also points to the possibility that the information technology industry is more receptive to foreign

4. Although the specific data are not presented in this paper, it was found that 92.7 per cent of respondents examined in this sample who intended to work in occupations requiring a university degree held a Bachelor's or higher level degree. In addition, 81.3 per cent of immigrants whose intended occupation requires a college diploma or apprenticeship satisfied this skill level or higher skill levels.

5. This conclusion is derived from the second digit of the NOC unit group codes. The skill level of occupations with a second digit of 1 is "Occupations usually requiring a university education." 
Table 4. Results from logistic regression.

\begin{tabular}{|c|c|c|c|c|c|c|c|c|c|}
\hline \multirow[b]{2}{*}{ Variable } & \multicolumn{3}{|c|}{ MODEL 1} & \multicolumn{3}{|c|}{ MODEL 2} & \multicolumn{3}{|c|}{ MODEL 3} \\
\hline & Coeff. & $\operatorname{Exp}(B)$ & Std Error & r Coeff. & $\operatorname{Exp}(B)$ & Std Error & Coeff. & $\operatorname{Exp}(B)$ & Std Error \\
\hline Sex (Male = 1) & 0.08 & 1.08 & 0.115 & 0.166 & 1.18 & 0.123 & 0.203 & 1.22 & 0.136 \\
\hline Age & $-0.021^{*}$ & 0.98 & 0.008 & $-0.024^{\star *}$ & 0.97 & 0.009 & $-0.018^{*}$ & 0.98 & 0.009 \\
\hline Visible Minority & $-0.430^{*}$ & 0.65 & 0.208 & $-0.390^{*}$ & 0.68 & 0.11 & $-0.431^{*}$ & 0.65 & 0.21 \\
\hline \multicolumn{10}{|c|}{ Immigrant Class (Skilled Worker=Reference) } \\
\hline Business & $1.099^{* *}$ & 3 & 0.347 & $1.333^{* * *}$ & 3.79 & 0.4 & $1.080^{* *}$ & 2.94 & 0.416 \\
\hline Family & -0.123 & 0.88 & 0.246 & -0.07 & 0.93 & 0.261 & -0.103 & 0.9 & 0.278 \\
\hline Provincial Nominee & 0.632 & 1.88 & 0.467 & 0.594 & 1.811 & 0.458 & 0.629 & 1.88 & 0.476 \\
\hline Refugee/Other & $-1.761^{*}$ & 0.17 & 0.83 & -1.105 & 0.33 & 0.888 & -1.078 & 0.34 & 0.906 \\
\hline \multicolumn{10}{|c|}{ Region of Origin (North America=Reference) } \\
\hline Africa & -0.278 & 0.76 & 0.352 & -0.328 & 0.72 & 0.341 & -0.278 & 0.76 & 0.344 \\
\hline Asia & -0.333 & 0.72 & 0.354 & -0.048 & 0.95 & 0.337 & -0.046 & 0.95 & 0.337 \\
\hline Carib., Central or South Am. & -0.436 & 0.65 & 0.398 & 0.323 & 1.38 & 0.398 & 0.338 & 1.4 & 0.395 \\
\hline Europe & -0.573 & 0.56 & 0.321 & -0.328 & 0.72 & 0.313 & -0.347 & 0.71 & 0.371 \\
\hline Middle East & -0.502 & 0.6 & 0.485 & -0.342 & 0.71 & 0.479 & -0.454 & 0.63 & 0.483 \\
\hline Oceania & -0.436 & 0.65 & 0.398 & $-0.995^{\star}$ & 0.37 & 0.435 & $-1.017^{*}$ & 0.36 & 0.438 \\
\hline Lives in Major CMA & $-0.422^{* * *}$ & 0.66 & 0.109 & $-0.351^{* *}$ & 0.7 & 0.119 & $-0.416^{\star * *}$ & 0.66 & 0.122 \\
\hline \multicolumn{10}{|c|}{ Level of Education (Bachelor's degree=Reference) } \\
\hline High school or lower & & & & 0.396 & 2.61 & 0.288 & 0.182 & 1.2 & 0.324 \\
\hline Some Postsecondary & & & & -0.309 & 0.73 & 0.25 & -0.399 & 0.67 & 0.257 \\
\hline Trade/College Complete & & & & $0.387^{*}$ & 1.47 & 0.176 & 0.268 & 1.31 & 0.202 \\
\hline Master's degree or higher & & & & $0.208^{* *}$ & 1.36 & 0.116 & $0.375^{\star *}$ & 1.45 & 0.119 \\
\hline \multicolumn{10}{|l|}{ Language Proficiency } \\
\hline English & & & & $0.016^{* * *}$ & 1.02 & 0.003 & $0.015^{* * *}$ & 1.02 & 0.003 \\
\hline French & & & & $0.011^{* * *}$ & 1.01 & 0.002 & $0.010^{* \star *}$ & 1.01 & 0.002 \\
\hline Previous Work Experience & & & & $1.200^{* * *}$ & 3.332 & 0.109 & $1.209^{\star * \star}$ & 3.335 & 0.111 \\
\hline SES of Intended Occupation & & & & & & & $-0.293^{\star *}$ & 0.75 & 0.076 \\
\hline \multicolumn{10}{|l|}{ Occupational Aptitudes } \\
\hline Clerical Perception & & & & & & & $-0.007^{\star *}$ & 0.99 & 0.002 \\
\hline Form Perception & & & & & & & -0.011 & 0.99 & 0.004 \\
\hline Finger Dexterity & & & & & & & 0.008 & 1.01 & 0.007 \\
\hline Manual Dexterity & & & & & & & 0.005 & 1 & 0.043 \\
\hline Motor Coordination & & & & & & & -0.004 & 1 & 0.008 \\
\hline Numerical Ability & & & & & & & -0.002 & 1 & 0.004 \\
\hline Spatial Perception & & & & & & & 0.001 & 1 & 0.004 \\
\hline Verbal Ability & & & & & & & -0.007 & 0.99 & 0.006 \\
\hline $\begin{array}{l}\text { Sample } \\
\text { Size }\end{array}$ & & 2678 & & & 2674 & & & 2674 & \\
\hline$-2 \mathrm{LL}$ & & -1379.47 & & & -1274.98 & & & -1254.76 & \\
\hline
\end{tabular}

Notes: Coeff. = Logistic Regression Coefficient, $\operatorname{Exp}(\beta)=$ Odds Ratio, S.E. = Standard Error Significance Levels: ${ }^{*} p<0.05 ;{ }^{* *} p<0.01 ;{ }^{* * *} p<0.001$

All coefficients and standard errors estimated based on bootstrap weights $=1,000$. 
credentials than other industries. Further, information systems analysts and consultants are one of only two of the most commonly held jobs for the non-match sample that require a university education. The second job requiring a university education is "post-secondary teaching and research assistant". Nearly three per cent of immigrants without occupational matches are working in these occupations, indicating that these individuals may have returned to post-secondary education to acquire Canadian credentials.

Results from the logistic regression models (Table 4) indicate that several factors influence the likelihood that a recent immigrant will obtain an occupational match within his or her first four years in Canada. The results from Model 1 reveal that several ascribed and demographic variables have statistically significant relationships with the dependent variable. Both age and visible minority status have negative relationships with the likelihood of an occupational match. Thus, older immigrants and visible minority immigrants are significantly less likely to obtain matches than younger immigrants and non-visible minority immigrants respectively. Of the immigrant admission class categories, business class immigrants are nearly three times more likely to obtain employment in their intended occupations than those who immigrate as skilled workers. However, there is a negative relationship between the refugee class and likelihood of an occupational match, indicating that immigrants who arrive under this admission class are less likely to obtain employment in their intended occupations than skilled workers.

Immigrants' regions of origin do not have statistically significant relationships with the likelihood of a job match when compared to immigrants who have arrived from North American nations. However, the area of Canada to which an individual immigrates does have a highly significant relationship with the likelihood of an occupational match. Individuals who immigrated to a major CMA (i.e., Montreal, Toronto, or Vancouver) are significantly less likely to obtain a match than those who immigrated to other areas of Canada. The probability of immigrants living in a major CMA obtaining an occupational match is 34 per cent lower than those living elsewhere in Canada when other ascribed and demographic variables are controlled.

When human capital factors are accounted for in Model 2, the "Refugee/Other" admission class variable is no longer significant, suggesting that variations in human capital explain the previous finding. However, the negative relationship that both age and visible minority status have with the likelihood of obtaining an occupational match persists in this model. Thus, even when variations in education, work experience, and language proficiency are controlled, older immigrants and visible minority immigrants continue to experience disadvantages in the labour market. Business class immigrants also remain significantly more likely to obtain an occupational match than skilled workers. The loss of statistical significance for the disadvantage of the refugee class (compared to the skilled worker class) when human capital factors are controlled indicates that the initial disadvantage that refugees were found to have in obtaining a job match can be explained by variations in their education, official langauge proficiency, and relevant foreign work experience. In addition, the "Oceania" region of origin does become statistically significant in Model 2, indicating that immigrants from this region are significantly less likely to obtain a job match than those from North American nations when differences in human capital are controlled.

Results from Model 2 indicate that the likelihood of recent immigrants obtaining employment in their intended occupations is highly influenced by human capital factors. High levels of education are advantageous to the immigrant population as those who hold a Master's degree or higher level degree are more likely to obtain an occupational match 
than immigrants whose highest level of education is a Bachelor's degree. Interestingly, immigrants who hold a college diploma or trade certificate are also more likely to obtain a job match than Bachelor's degree holders. English and French language proficiency levels are also highly significant predictors of recent immigrants' success in obtaining employment in their intended occupations. Results indicate that the higher an immigrant's proficiency in English or French, the more likely it is that he or she will obtain an occupational match within four years of arriving in Canada. The last human capital factor examined in Model 2 , foreign work experience in an immigrant's intended occupation, also has a strong and positive relationship with the likelihood of an occupational match. Immigrants who were employed in their intended occupations prior to immigrating are three times more likely to obtain a match than those without this type of work experience.

Controlling for the occupational characteristics in Model 3 has little effect on the significance levels of the previously entered variables. All but one of the ascribed, demographic, and human capital factors found to be statistically significant predictors in Model 2 continue to have an influence on occupational match. When occupational characteristics are controlled, immigrants with college diplomas and trades certificates are no longer more likely to obtain a job match than Bachelor's degree holders. Therefore, when one accounts for variations in the type of occupations sought by immigrants with this type of training, there is no significant difference in the likelihood of a job match between these two types of education. Results from this model also indicate that the SES of intended occupation is a highly significant predictor of the likelihood of an occupational match; the higher the status of an immigrant's intended occupation, the less likely it is that he or she will obtain a match. Specifically, the data indicate that with an increase of one in the SES score of an immigrant's intended occupation, the likelihood of obtaining employment in that occupation decreases by 25 per cent. Thus, recent immigrants who seek lowstatus occupations in Canada are much more likely to obtain employment in their desired occupations than those seeking high-status occupations.

The inclusion of occupational aptitudes in Model 3 provides less convincing results regarding the influence of intended occupation characteristics on the likelihood of a match. While two of the aptitude variables, clerical perception and form perception, indicate significant and negative relationships with the likelihood of a match, these results are much smaller in magnitude than the effect of an intended occupation's status. However, it can be stated from these results that the higher the aptitude in clerical or form perception required of an immigrant's intended occupation, the more likely it is that he or she will obtain an occupational match. ${ }^{6}$

\section{Discussion}

Results from these analyses reveal that predictors of recent immigrants' occupational attainment in Canada are varied. The descriptive data provide some information about the desired and actual occupations of immigrants who arrived in Canada between 2000 and 2001, indicating that slightly more than 20 per cent of immigrants obtained an occupational match at the NOC unit group level of classification within four years of arrival. However,

6. This interpretation is counter-intuitive due to the coding of the aptitude variables due to the use of the normal curve to produce midpoint scores. Higher scores equate to a lower level of aptitude required for the occupation. Refer to Appendix A for further explanation of the coding of this variable. 
when matches at broader levels of occupational classification are considered, the percentage with occupational matches rises. This demonstrates how misleading broad occupational categorizations can be when studying occupational matching among the immigrant population. For example, an immigrant who intends to work as a physician, yet is employed as a hospital orderly, would be considered to have an occupational match at the skill type level, as both of these occupations fall under the broad skill type classification of "Health Occupations." Thus, relatively high percentages of occupational matches among immigrants can be reported if a broad level of occupational classification is employed, despite the fact that such matches may not be commensurate with immigrants' education or training.

The descriptive data also indicate that a large portion of recent immigrants intend to work in occupations that require a university education, as one third of this cohort seeks employment in professional occupations in the natural and applied sciences. The high level of education among immigrants in this cohort is also reflected by the large percentage who hold a Bachelor's or higher level degree. However, of those who did not obtain an occupational match within their first four years in Canada, only two of the five most frequently held occupations were those that require a university education. Thus, there is some evidence that immigrants without an occupational match are employed in occupations for which they are overeducated, although there is a wide range of occupations held by respondents in the non-match sub-sample. This provides further evidence that immigrants experience a devaluation of their credentials in the Canadian labour market and that they likely state their intended occupations without a great deal of knowledge of how their credentials will be assessed in Canada. In addition, as discussed previously, these results are representative of a fairly unique group of immigrants, primarily those who arrived under the "Skilled Worker" admission class. Thus, the education results are skewed in the direction of higher levels of education and, by extension, a large portion of the sample studied intend to work in occupations requiring a university education.

The logistic regression results provide some indication of discrimination in the Canadian labour market based on age and visible minority status. Younger immigrants are more likely to obtain occupational matches than older immigrants, while visible minority immigrants are at a disadvantage when compared to non-visible minority immigrants. However, an immigrant's sex is not found to be highly influential in obtaining a job match. Therefore, while discrimination based on visible minority status and age appears to persist even when human capital and occupational characteristics are controlled, sex discrimination is not apparent. However, the fact that women who arrived in Canada as dependents are largely excluded from this study must be considered. Because only those who stated an intended occupation on their application for immigration (largely principal applicants in the skilled worker class) are included in this analysis, immigrant women only represent about one quarter of the sample studied. Thus, research that specifically examines occupational matching among women who arrive as dependents may provide further insight into their employment outcomes in Canada.

A noteworthy finding from the regression results is that individuals who immigrate to Montreal, Toronto, or Vancouver are significantly less likely to obtain employment in their intended occupations than those who live elsewhere in Canada. While there has been increasing attention given to the financial success of immigrants who live outside of Canada's major cities (Reitz 2003a; Bernard 2008), these results add another dimension to these findings, indicating that immigrants are also more successful in obtaining employment in their intended occupations outside of Canada's main immigrant-receiving cities. 
This finding may be reflective of Reitz's assertion that immigrants in Canada's major cities face a large amount of competition for jobs, both from other immigrants and from new labour market entrants with Canadian credentials (2003a).

In addition to the increased competition for jobs in the major CMAs, this result also raises questions about Canadian employers' receptiveness to immigrant workers in these areas. While it is often assumed that immigrants are more readily accepted by employers in major CMAs due to their greater exposure to immigrants and the cultural diversity represented within these cities, this could be an inaccurate assumption. Smaller communities often voice concern over their economic survival and, because immigrants are typically identified as a source of new and educated workers by the Canadian government, immigrants may in fact be seen as a valuable resource to the economies of smaller cities and towns. In fact, a 2006 news article reported that some Ontario employers are concerned that immigrants are unaware of job opportunities outside of the Greater Toronto Area (GTA); these employers indicate that they do not have a large enough supply of skilled and educated immigrants in non-GTA regions (Toronto Star 2006). If immigrants' skills are indeed in higher demand outside of the major CMAs, this could explain the greater occupational attainment for immigrants in these areas.

The admission class of immigrants is also found to be somewhat influential to immigrants' occupational attainment in Canada. Business class immigrants experience greater success in obtaining occupational matches than those who arrive under the skilled worker class. In fact, this group of immigrants is almost three times more likely to obtain a match than skilled workers when all other factors in the model are controlled. Although the higher levels of human capital possessed by business class immigrants may be identified as a potential explanation of their success, this group is more likely to obtain an occupational match even when variations in human capital are accounted for. Thus, the advantage that business class immigrants enjoy may be due to other unmeasured characteristics. The entrepreneurial nature shared by many immigrants in this group, their low dependence on ethnic social networks, and their possession of greater financial capital than other immigrants may also influence their employment success in Canada (Marger 2001).

While some ascribed and demographic characteristics influence the likelihood of an occupational match, several human capital factors are highly significant predictors of this aspect of immigrants' occupational attainment. In particular, proficiency in an official language and work experience in one's intended occupation prior to arriving in Canada have positive relationships with the likelihood of obtaining a match. The results indicate that the higher an immigrant's proficiency in English or French, the greater the likelihood of obtaining employment in his or her intended occupation. This supports previous studies' conclusions that proficiency in an official language is beneficial to immigrants' occupational attainment in Canada (Abu-Laban 1992; Thompson 2000; Grondin 2007). These results also offer support to the assumptions of human capital theory as proficiency in an official language is a marketable skill for immigrants which can be improved through additional education and training. This skill can therefore be strengthened over time and contribute to immigrants' future employment success.

The significant advantage of immigrants with foreign work experience in their intended occupations also supports the human capital assumption that the more relevant work experience an individual accumulates, the greater success he or she will have in the labour market. The positive relationship between the previous work experience variable and the likelihood of an occupational match suggests that foreign work experience may 
be more valued within the Canadian labour market than previous literature has suggested. Although earnings studies generally find that foreign work experience yields no financial advantage to immigrants (Aydemir and Skuterud 2005; Goldmann et al. 2009), results from this study indicate that immigrants who have worked in their intended occupations prior to immigrating are more likely to obtain occupational matches than those without pre-migration experience in their intended occupations. This discrepancy may be due to the measurement of foreign work experience itself. While previous literature tends to approximate years of foreign work experience, often comparing the earnings return of years of Canadian experience to foreign experience, this study specifically measures whether or not an immigrant has foreign work experience in his or her intended occupation. Therefore, although foreign work experience may not be as valued as Canadian work experience, results from this study indicate that immigrants who have experience working in their intended occupations prior to immigrating are significantly more likely to obtain an occupational match than those without this type of work experience.

While these results do not necessarily indicate that Canadian employers formally recognize immigrants' foreign work experience, they do show that this experience provides some type of advantage over other immigrants in the Canadian labour market. This may be due to the knowledge obtained with experience in one's intended occupation that can be drawn upon to better identify useful networks in seeking employment in his or her particular field. Knowledge derived from previous experience in an immigrant's intended occupation may also help him or her obtain recognition of foreign credentials or receive promotions more quickly than immigrants who do not possess this type of knowledge. This may be particularly true of immigrants who must write technical exams or undergo other certification procedures in order to practice their intended occupations in Canada.

In addition to the benefits of work experience, the regression results indicate that immigrants who arrive in Canada with a graduate or professional degree are more likely to obtain an occupational match than Bachelor's degree holders. The fact that immigrants with Master's degrees and higher level degrees are more likely to obtain matches than those with Bachelor's degrees may be attributable to different but related aspects of the hiring process. First, immigrants with credentials above the minimum educational requirement of a job likely have an advantage due to their place in the hiring "queue." According to queuing theory, employers often form ideas of a particular order, or queue, of potential employees (Reskin and Roos 1990). Thus, individuals who hold credentials signifying higher abilities than others are placed higher in the queue; they will get the job before individuals with "lesser" credentials. Higher-level degrees also act as "market signals" to employers, indicating the abilities of a potential employee (Hunter 1986: 99). Therefore, immigrants with a level of education higher than a Bachelor's degree may be more desirable because their credential signifies increased specialization that may translate into a greater ability to learn "certain technical and social requirements" of their intended occupations (Hunter 1986: 100). Thus, even though Bachelor's degree holders may possess the skill level required to work in their intended occupations, they experience less success in obtaining employment in these occupations than those who have more than the minimum skill level required. This finding may also reveal something about the devaluation of foreign credentials. That is, while employers may be wary of foreign undergraduate degrees, it appears as though higher degrees do not suffer from a similar devaluation. Reitz (2003b) suggests that immigrants may benefit from the fact that degrees above the Bachelor's level are more specialized and may therefore lessen the extent 
to which they are devalued compared to undergraduate degrees. This finding is may also be indicative of the fact that immigrants with higher-level degrees face less competition in the labour market than those who hold only a Bachelor's degree.

Although several human capital factors are significant predictors of occupational match, the majority of occupational aptitudes are not. One exception is the socio-economic status of an immigrant's intended occupation. The results reveal that the higher the SES of an immigrant's intended occupation, the less likely it is that he or she will obtain an occupational match. These results suggest that there is a form of social closure within the Canadian labour market, as immigrants who intend to work in higher status occupations face more exclusionary practices than those who seek lower status occupations. While it may be argued that higher status occupations are more difficult to obtain from the outset due to lengthier amounts of required education or training, the vast majority of immigrants studied arrived in Canada with the appropriate educational credentials (in terms of skill level) for their intended occupations (see note 4). In addition, the relationship between the SES of intended occupation and the likelihood of obtaining an occupational match persists when ascribed, demographic, and human capital factors are controlled. Thus, the process of social closure is evident as recent immigrants to Canada experience greater difficulty gaining access to high-status positions in the labour market.

\section{Conclusion}

The results of this study reveal that there are several predictors of the occupational attainment of recent immigrants to Canada. Among the ascribed and demographic characteristics, an immigrant's age, visible minority status, and whether or not he or she resides in a major CMA are significant predictors of occupational match. Older immigrants and visible minority immigrants experience a disadvantage in obtaining occupational matches in the Canadian labour market, possibly due to discriminatory processes. Individuals who immigrate to a major CMA are also significantly less likely to obtain an occupational match than those who reside elsewhere.

Human capital theory is largely supported by the results of this study, as several achieved characteristics are highly significant predictors of the likelihood of an occupational match. Immigrants who arrive with the highest levels of education are more likely to obtain job matches than Bachelor's degree holders. In addition, immigrants with high levels of proficiency in English or French are more likely to obtain occupational matches than those with lower levels of proficiency in Canada's official languages. Immigrants who have work experience in their intended occupations prior to arrival in Canada are also more likely to obtain matches than those without this type of work experience.

Results from the socio-economic status scores of immigrants' intended occupations provide some support to the theory of social closure. The data suggest that the process of social closure is particularly effective in preventing immigrants from obtaining highstatus occupations. These findings may be reflective of Parkin's assertion that certain occupational groups, typically representing high-status occupations, can limit others' access to their occupations by controlling institutionalized procedures such as licensing, credential recognition, or specific training (1979). The remaining occupational characteristics do not provide consistent evidence and thus a general theory of the relationship between required aptitude levels of immigrants' intended occupations and the likelihood of obtaining occupational matches cannot be developed. 
Several factors are influential to immigrants' employment success when examining the concept of occupational matching among recent immigrants to Canada. While the assumptions of human capital theory are largely supported in this study, theories that address the processes of discrimination and social closure are also strengthened by the results. Thus, while recent immigrants' achieved characteristics are influential to their occupational attainment in Canada, there is evidence that larger, societal-level practices also play a role in preventing them from obtaining employment in their intended occupations.

\section{References}

Abu-Laban, Y. 1992. Ethnicity and occupational inequality: A reconsideration. The Alberta Journal of Educational Research 38(3):205-18.

Alboim, N., R. Finnie, and R. Meng. 2005. The discounting of immigrants' skills in Canada: Evidence and policy recommendations. IRPP Choices (Institute for Research on Public Policy) 11(2):1-26.

Anisef, P., R. Sweet, and G. Frempong. 2003. Labour market outcomes of immigrant and racial minority graduates in Canada. Working Paper No. 23. Toronto: CERIS.

Aydemir, A. and M. Skuterud. 2005. Explaining the deteriorating entry earnings of Canada's immigrant cohorts: 1966-2000. Canadian Journal of Economics 30(2): 641-71.

Basran, G.S. and L. Zong. 1998. Devaluation of foreign credentials as perceived by visible minority professional immigrants. Canadian Ethnic Studies 30(3): 6-23.

Bauder, H. 2003. "Brain Abuse," or, The devaluation of immigrant labour in Canada. Antipode 35(4): 699-717.

Bernard, A. 2008. Immigrants and the hinterlands. Perspectives on Labour and Income Series (Catalogue No. 75-001-X). Ottawa: Statistics Canada.

Blishen, B. 1967. A socio-economic index for occupations in Canada. Canadian Review of Sociology and Anthropology 4(1): 41-53.

Boyd, M. and X. Cao. 2009. Immigrant language proficiency, earnings, and language policies. Canadian Studies in Population 36(1-2): 63-86.

Boyd, M. and G. Schellenberg. 2007. Re-accreditation and the occupations of immigrant doctors and engineers. Canadian Social Trends Winter: 2-10.

Boyd, M. and D. Thomas. 2002. Skilled immigrant labour: Country of origin and the occupational locations of male engineers. Canadian Studies in Population 29(1): 71-99.

- 2001. Match or mismatch? The employment of immigrant engineers in Canada's labor force. Population Research and Policy Review 20: 107-33.

Elliott, J.R. and R.A. Smith. 2001. Ethnic matching of supervisors to subordinate work groups: Findings on "bottom-up" ascription and social closure. Social Problems 48(2): 258-76.

Fong, E. and X. Cao. 2009. Effects of foreign education on immigrant earnings. Canadian Studies in Population 36(1-2): 87-110.

Frenette, M. and R. Morissette. 2003. Will they ever converge? Earnings of immigrant and Canadian-born workers over the last two decades. Analytical Studies Branch Research Paper Series (Catalogue No.11F0019MIE2003-215). Ottawa: Statistics Canada.

Fuller, S. and L.F. Vosko. 2008. Temporary employment and social inequality in Canada: Exploring intersections of gender, race, and immigration status. Social Indicators Research 88(1): 31-50.

Galabuzi, G-E. 2006. Canada's Economic Apartheid: The Social Exclusion of Racialized Groups in the New Century. Toronto: Canadian Scholar's Press. 
Goldmann, G., A. Sweetman, and C. Warman. 2009. The Economic Return on New Immigrants' Human Capital: The Impact of Occupational Matching. Working Paper No. 21. Canadian Labour Market and Skills Researcher Network. http://www.clsrn.econ.ubc.ca/workingpapers/CLSRN\%20 Working\%20Paper\%20no.\%2021\%20-\%20Goldmann,\%20,Warman,\%20Sweetman.pdf (retrieved April 2, 2009).

Grondin, C. 2007. Knowledge of official languages among new immigrants: How important is it in the labour market? (Catalogue No. 89-615-XIE). Ottawa: Statistics Canada.

Hou, F. and T.R. Balakrishnan. 2004. The economic integration of visible minorities in contemporary Canadian society, in Social Inequality in Canada: Patterns, Problems, and Policies, edited by J. Curtis, E. Grabb, and N. Guppy. 4th edn. Toronto: Pearson Education Canada, pp. 273-84.

Hunter, A.A. 1986. Class Tells: On Social Inequality in Canada. 2nd edn. Toronto: Butterworths. Kaufman, R.L. 2002. Assessing alternate perspectives on race and sex employment segregation. American Sociological Review 67:54-72.

Kazemipur, A. and S.S. Halli. 2001. The changing colour of poverty in Canada. Canadian Review of Sociology and Anthropology 38(2):217-38.

Li, P.S. 2008. The role of foreign credentials and ethnic ties in immigrants' economic performance. Canadian Journal of Sociology 33(2):291-310.

- 2003. Destination Canada: Immigration Debates and Issues. Toronto: Oxford University Press.

. 2001. The market worth of immigrants' educational credentials. Canadian Public Policy 27(1):23-38.

2000. Earning disparities between immigrants and native-born Canadians. The Canadian Review of Sociology and Anthropology 37(3):289-311.

Man, G. 2004. Gender, work and migration: Deskilling Chinese immigrant women in Canada. Women's Studies International Forum 27(2):135-48.

Marger, M.N. 2001. The use of social and human capital among Canadian business immigrants. Journal of Ethnic and Migration Studies 27(3):439-53.

McDade, K. 1988. Barriers to Recognition of the Credentials of Immigrants in Canada. Ottawa: Institute for Research on Public Policy.

HRSDC (Human Resources and Skills Development Canada). 2001. National Occupational Classification: Index of Titles. Ottawa: Human Resources and Skills Development Canada.

Parkin, F. 1979. Marxism and Class Theory: A Bourgeois Critique. London: Tavistock.

Pendakur, K. and R. Pendakur. 2007. Minority earnings disparity across the distribution. Canadian Public Policy 33(1):41-61.

. 2000. Ethnicity and earnings, in Immigrants and the Labour Force: Policy, Regulation, and Impact, edited by R. Pendakur. Montreal: McGill-Queen's University Press, pp. 159-91.

Reitz, J.G. 2003a. Social risks for newcomers to Canada: Issues respecting the role of government in Ontario. Panel on the role of government in Ontario (Research Paper No. 11). http:// www.law-lib.utoronto.ca/investing/reports/rp11.pdf (retrieved May 30, 2009). - 2003b. Occupational dimensions of immigrant credential assessment: Trends in professional, managerial and other occupations, 1970-1996. http://www.utoronto.ca/ ethnicstudies/credential.pdf (retrieved 10 May, 2008).

. 2001a. Immigrant skill utilization in the Canadian labour market: Implications of human capital research. Review. Ottawa: Department of Canadian Heritage, Citizen's Participation and Multiculturalism.

2001b. Immigrant success in the knowledge economy: Institutional change and the immigrant experience in Canada 1970-1995. Journal of Social Issues 57(3):579-613.

Reskin, B. and P. Roos. 1990. Job Queues, Gender Queues: Explaining Women's Inroads into Male Occupations. Philadelphia: Temple University Press.

Roscigno, V.J., L.M. Garcia, and D. Bobbitt-Zeher. 2007. Social closure and processes of race/sex employment discrimination. The Annals of the American Academy of Political and Social Science 609(1):16-48. 
Roscigno, V.J., S. Mong, R. Byron, and G. Tester. 2002. Age discrimination, social closure and employment. Social Forces 86(1):313-34.

Sanders, J., V. Nee, and S. Sernau. 2002. Asian immigrants' reliance on social ties in a multiethnic labor market. Social Forces 81(1):281-314.

Statistics Canada. 2006. Micro-Data User Guide: Longitudinal Survey of Immigrants to Canada, Wave 2. Ottawa: Statistics Canada, Special Surveys Division.

Thompson, E.N. 2000. Immigrant occupational skill outcomes and the role of region-of-originspecific human capital. Applied Research Branch, Strategic Policy (Catalogue No. W-00-8E). Ottawa: Human Resources Development Canada.

Tomaskavic-Devey, D., M. Thomas, and K. Johnson. 2005. Race and the accumulation of human capital across the career: A theoretical model and fixed effects application. American Journal of Sociology 111:58-89.

Toronto Star. 2006. Website links workers and jobs. March 11.

Weber, M. 1968. The Theory of Social and Economic Organization. Translated by A.M. Jenderson and T. Parsons. New York: The Free Press.

Weeden, K.A. 2002. Why do some occupations pay more than others? Social closure and earnings inequality in the United States. American Journal of Sociology 108(1):55-101. 


\section{Appendix A}

\begin{tabular}{|c|c|}
\hline Variable & Definition/Code \\
\hline Sex & Males coded "1", Females coded "0" \\
\hline Age & Continuous variable between ages $25-64$ \\
\hline Visible Minority Status & Visible Minorities coded "1", Non-Visible Minorities coded "0" \\
\hline $\begin{array}{l}\text { Census Metropolitan } \\
\text { Area (CMA) }\end{array}$ & $\begin{array}{l}\text { Lives in Major CMA (Montreal, Toronto, Vancouver) coded "1", Lives in other } \\
\text { area coded " } 0 \text { " }\end{array}$ \\
\hline $\begin{array}{l}\text { Immigrant Admission } \\
\text { Class }\end{array}$ & $\begin{array}{l}\text { Set of dummy variables, Skilled worker is reference category. } \\
\text { Note: Two of the original admission class categories provided in the } \\
\text { Longitudinal Survey of Immigrants to Canada (i.e. "Refugee" and "Other") } \\
\text { were collapsed together due to small counts. }\end{array}$ \\
\hline $\begin{array}{l}\text { Highest Level of } \\
\text { Education Obtained } \\
\text { Outside Canada }\end{array}$ & $\begin{array}{l}\text { Set of dummy variables, Bachelor's degree is reference category. } \\
\text { Note: Master's Degree or Higher includes Master's degree, professional } \\
\text { degree in dentistry, veterinary, optometry, law or theology, or Doctorate. }\end{array}$ \\
\hline $\begin{array}{l}\text { Language Proficiency } \\
\text { Scores }\end{array}$ & $\begin{array}{l}\text { Calculated by Statistics Canada after data on language proficiency were } \\
\text { collected. The original scores range from } 0 \text { to } 1 \text { and are based on several } \\
\text { LSIC language questions (Statistics Canada 2006). More interpretable } \\
\text { scores were created by multiplying original scores by } 100 \text {. }\end{array}$ \\
\hline $\begin{array}{l}\text { Previous Work } \\
\text { Experience in Intended } \\
\text { Occupation }\end{array}$ & $\begin{array}{l}\text { Past occupation in country of origin the same as intended occupation (NOC } \\
\text { unit group level) coded "1", others coded "0" }\end{array}$ \\
\hline $\begin{array}{l}\text { Socio-economic status } \\
\text { (SES) scores }\end{array}$ & $\begin{array}{l}\text { Continuous level variables, calculated in a similar fashion as Blishen (1967) } \\
\text { SES scores using Statistics Canada data on education and income. }\end{array}$ \\
\hline Occupational Aptitudes & $\begin{array}{l}\text { The aptitude variables represent aptitudes required for the intended } \\
\text { occupation reported prior to immigration. Coded in the } 2001 \mathrm{NOC} \text { with } \\
\text { a number between } 1 \text { and } 5 \text { which are based on the normal curve of the } \\
\text { Canadian work force. To treat as continuous variables, midpoints for each } \\
\text { of the points on the normal curve were used. Lower midpoints correspond } \\
\text { with higher levels of aptitude (e.g. the midpoint of } 5.5=\text { level of aptitude that } \\
\text { applies to the top } 10 \% \text { of the working population). Refer to the } 2001 \text { NOC } \\
\text { Career Handbook for definitions of occupational aptitudes. } \\
\text { Note: Due to high multicollinearity with the SES of intended occupation, the } \\
\text { General Learning Ability aptitude was excluded from the model. }\end{array}$ \\
\hline
\end{tabular}

